\title{
Organizational trust or beyond appearances
}

\author{
Maria Irina Dromereschi, „Al. I. Cuza” University of Iasi, Romania
}

\begin{abstract}
People and organizations to whom I am giving life to have an enormous need to trust and be trustworthy. Trust represents a fragile asset who needs to be invested in, which is difficult to obtain and takes time to obtain it, but which can be easily broken. Paradoxically, it is a universal trade currency, world-widely understood and appreciated. The relations based on trust are those which determine a company to grow and create a competitive advantage. Trust generates trust. It is the one that inspires and motivates, requires the preservation of a certain set of values, mainly sincerity, fairness, perseverance and a real preoccupation for meeting the needs of other people.
\end{abstract}

\section{Keywords}

organizational trust, forms of organizational trust, patterns of organizational trust, values of the organization.

\section{JEL Codes: D23, J53.}

\section{Introduction}

The word 'trust' comes from Latin and it means "in good faith". Trust comes with experience. Experience starts with a grain of trust. The shortest definition of trust seems to be having faith in one person's integrity and abilities. A partnership based on trust is one in which it is acceptable to make mistakes in order to carry on the relationship. Trust is based on credibility. We trust somebody when we feel that that person has the means to achieve what he has promised or what it necessary to be achieved. The necessary means include fair competence and behavior. We tend to believe that trust is inspired by a person. But this is only a part of trust. Francois de la Rochefoucauld said that "the trust we put in ourselves makes us feel the trust in others" thus, trust is a two-way street. It is not enough to invest trust in someone / the others. The reciprocal is necessary or at least the feed-back. These things are probably easier to be seen in personal relations but invisibly they are amplified in costs, respectively in the revenue of the organization. If when we hire the focus is put on the candidates' skills, the key to the best performances lies in their attitudes. Full of altruism, Douglas McGregor stated in 1960 in 'The Human Side of Enterprise" that trust is 'knowing that you will not take disloyal advantage of me, deliberately or accidentally, being aware or not. I can put my situation, my status, my esteem, my relations, my job, my career and even my life into your hands'. Even if it is far more optimistic than we could afford nowadays, we need to admit that there are situations when we could not think to do otherwise.

\section{Trust, from preoccupation to subject of study and research}

Beyond the subjectivity attributed to trust, this is more than a preoccupation, it is a subject of research from various reasons. The one that concerns us is the organizational dimension of this concept and not only for the psychological implications but for those economic and social, too. After 1960, there was a qualitative progress of understanding the phenomenon of 
trust after combining interdisciplinary efforts - Psychology, Sociology, Law, Economics, Political Science. Its direct applicability to the organizational and managerial problem is more recent. We can see a progressive increase of interest and importance of the phenomenon of trust in Political Science. Even if its social connotations had been inferred since ancient times (Confucius 551-479 B.C.), the evolution of the concept took place progressively by being aware of its role at all levels: personal - individual, interpersonal, institutional - organizational and social. Misztal, B.A. (1996) in Trust in modern Societies states that this interest is manifest due to the fact that the society is aware that "the bases for social cooperation, solidarity and consensus have been eroded and thus we need to find new alternatives". The accentuation of interdependencies in a world of more and more specialized role-plays, the institutions with or without previous bookkeeping calculus show that we are vulnerable precisely to what is supposed to be implicit in a relation - trust. The erosion of citizens' trust in society, as a result of the erosion of the social concepts more or less modern (languages, games, money, liberties, nations, governments, universities, corporations and all the other institutions) remains a problem of present times. Psychologists have initially associated it to generosity. (Deutsch M. 1958). Generosity is circumcised to trust together with a part of its attributes. Morton Deutsch in Trust and suspicion, connected the phenomenon of trust to behavioral predictability, whereas Hovland and its partners (1953) stated that the most important feature of trust is motivation. Starting with the ' 60 , together with the development of human resources attributions, the problem of interpersonal trust has been analyzed in the work context, expanding it subsequently to the organizational level. The author starts from situational aspects (actions and situations) and not from the dispositional ones (attitudes, personality) because the first ones can be easily expressed quantitatively through indexes like the cooperation ratio and trust in situations such as 'the prisoner's dilemma' with applications in the theory of games (Nash's equilibrium) taking into consideration the risk factor in choosing the strategy, the principle being as follows: a low risk indicates higher degree of cooperation and implicitly trust. In the following years, the studies and researches began to expand on structure, interdependence and relation between trust and cooperation from interpersonal level to the organizational one. The process character of trust begins to be made obvious, and it is restated by Zand D. (1972) by the gradual and self-assertive character. The 70's and the 80 's brought only an evolution of the previous concepts adding new components to the structure of trust, respectively: altruism (Frost T. and partners 1978), reasoning, business sense and character (Gabbaro L. 1978) and respect (Webber, 2002). The year of 1996 is important due to the most comprehensive synthesis on this subject, published by R.M. Kramer and T.R. Tyler: Trust in Organizations: Frontiers of Theory and Research.

The beginning of the new millennium brings a close-up of the institutionalization of research activities. Three international workshops were organized on the theme 'Trust in and between organizations' (Amsterdam 2001, 2003 and 2005) which reunited specialists from a wide variety of disciplines. The year of 2001 brought about the first specific organization, First International Network on Trust (FINT).

\section{Organizational trust}

The increasing interest in the concept of organizational trust has the following arguments: 1.it is in the interest of the performance of the organization (Dirks and Ferrin, 2001); 2.it has a positive effect on results, cooperation and work efficiency, moderating directly or indirectly, acting over the main determinants of performance (Zaheer and partners, 1998);

3.it increases the advantages of the companies which develop trust from inside (the internal climate) to outside (external partners)(Kets de Vrie, 2001);

4.the organizations with a high level of trust (internal) will be more successful, more adjustable and more innovating than the ones with low levels of trust (Shockley-Zalabak, 2000); 
5.it becomes an important aspect for those companies which are in competition on the world markets where incertitude and risk are high and the partners' culture, values and goals can be very different (Huff \& Kelley, 2003);

6.the benefits of trust can be found on social and economic levels, on national and international levels, 'anywhere in the world, trust facilitates economic cooperation' (James \& Sycuta, 2004).

A close look over the orientation of studies and research in this field shows the existence of three qualitative leaps:

1.passing from believing that trust is a trait belonging to the field of personality psychology to considering it as being located in the context of social-economic life;

2.passing from the correlation of trust with two-three psycho-organizational and managerial variables to its progressive correlation to all variables that hint at organizational behaviors;

3.passing from the predominantly theoretical perspective to the predominantly practicalapplicable perspective.

The organizational trust has gained the interest of several sciences (Psychology, Sociology and Economics) which offered their instruments in order to find a definition that is both comprehensive and precise, offering in fact the valences of this concept born from an extremely dynamic reality. In economic terms, the organizational trust is acknowledged as that expectancy related to the way in which the other party will behave in a possible transaction or / and in confrontation with risk. A party binds itself to rely on the other in order to attain a certain goal, the degree of the anticipated risk being one of the game rules, each part having something to gain in the final result of the transaction. Whatever the definitions may be, they have in common three elements: the anticipation of a behavior (prediction of an expected behavior), the natural effect of the probability calculus (the expectancy of a relation which will function) and assuming the risk (vulnerability).

The forms of organizational trust require several criteria of classification.

1.if we take into consideration the way in which the risk is assumed, trust can be: selfrevealing, contractual and of safety (by 'reading' the other's intentions; it has a marked intuitive character);

2.if we take into consideration the degree to which trust has been cultivated within a personal relation: trust based on calculus (Calculus Based Trust - CTB) and trust based on identification (Identification-Based Trust - IBT);

3.if we take into consideration the criteria of depth / intensity of relations, we can have trust based on abstention / prevention (in poor consolidated relations and as a rule in the incipient ones), trust based on knowledge (requires holding adequate information and an experience with previous actions) and trust based on identification (requires the existence of an emotional connection).

Without the specific criteria (to order several types) but considering only the specific types, there have been identified the following: strategic trust (an expectation related to somebody else's behavior regarding a specific action), generalized trust (the inclination to trust most people as a personality feature) and particularized trust (given on the basis of some common characteristics with those of a group or of a people network having as background the affiliation to that specific group).

\section{Models of organizational trust}

The applicative character of research and preoccupation with organizational trust did not delayed the occurrence of some explanatory models of the phenomenon. Each of these models is the result of knowledge, experience and application field where it is recommended.

Douglas, Creed and Miles (1996) elaborated the Model of mutual evaluation of trust (see picture 1). 


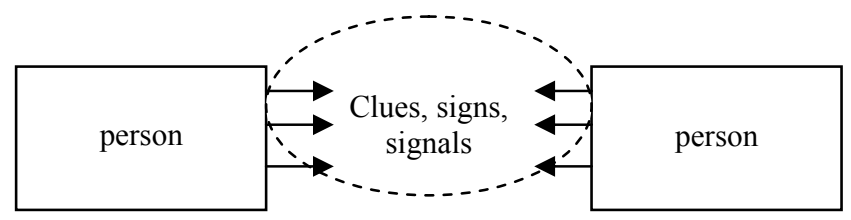

Picture.1. The model of mutual evaluation of trust

Source: Douglas, W., Creed, E., Miles, R.E. (1996), Trust in organizations - a conceptual framework linking organizational forms, managerial philosophies and opportunity costs of control în Kramer, R.M., Tyler, T. (ed.), Trust in organizations, Frontiers of Theory and Research, Sage Publications, Londra

According to this model, individuals keep mental agreements regarding the history of trust related to the behaviors that involved them and the others. The parties involved in the relation evaluate, consciously or unconsciously, the level of trust starting from clues, signals coming from the communication and behavior of the others. Each party wishes to know if the other party could affect the state of welfare, if it has an opportunistic orientation or one towards the satisfaction of the common interest. This model has the advantage of unconscious processes, underestimated by the other models, processes which can foresee trust, and the disadvantage of not giving the proper attention to common formal objectives and work cooperation. Mayer, Davis and Schoorman (1995) elaborated a model of moderators of trust (see picture 2).

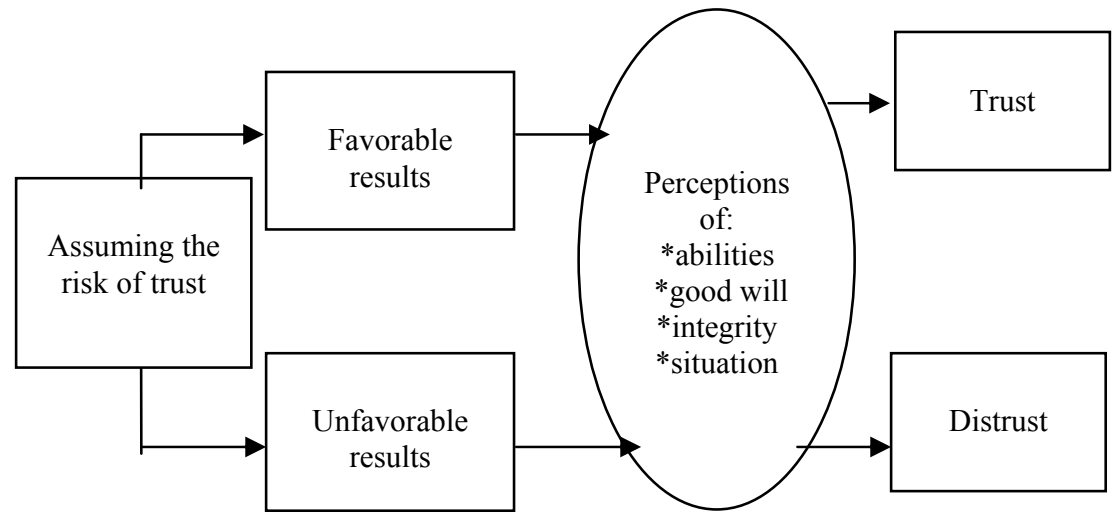

Picture.2. The model of moderators of trust

Source: Mayer, R.C., Davis, J.H., Schoorman, F.D. (1995), An integration model of organizational trust, The Academy of Management Review Briarcliff Manor, iulie, vol.20, Iss. 3, p.709-835

Mayer, Davis and Schoorman consider that the dynamics of the nature of trust consists in the multiplication of investment in trust in positive receivers (favorable results) and in obtaining unfavorable results, respectively distrust in negative receivers. Trust or distrust are though results mediated by the 'lens' of the perception of abilities, good will, integrity and situational context. The model is oriented towards the finalities of relations, catches the progress, takes into consideration the moderators of trust and the circumstances but it does not include the common needs of the individuals. Jones and George (1998) elaborated a model of experience of trust (see picture 3). 


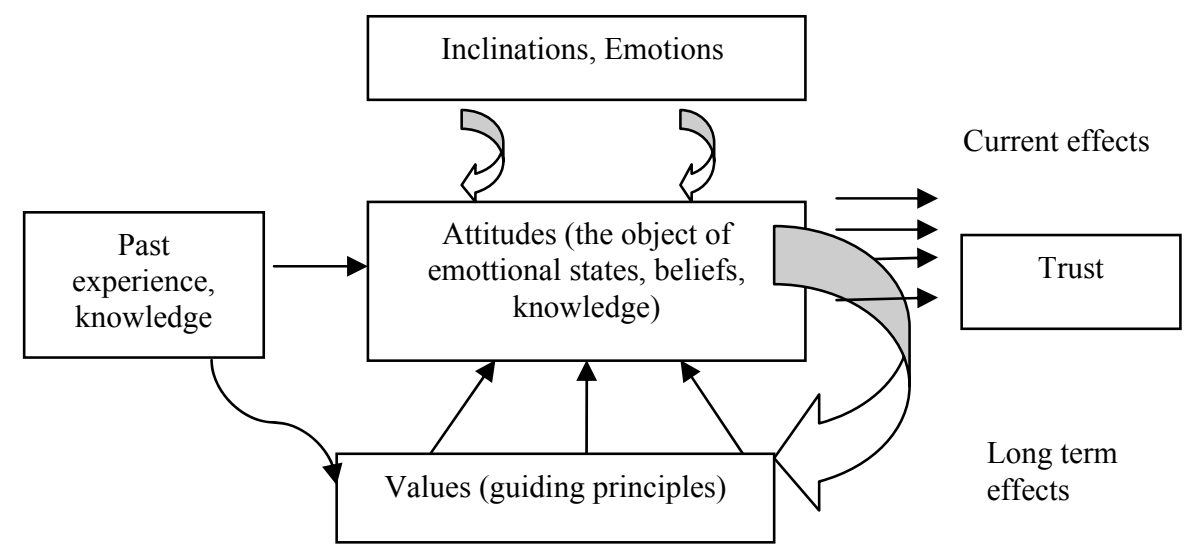

Picture.3. The model of experience of trust

Source: Jones, G.R., George, J.M. (1998), The experience and evolution of trust: Implications for cooperation and teamwork, The Academy of Management Review, 23, 3, p. 531-546

The fundament of this model lies in the system of the individual's values. The values are brought forward by principles, together guiding the individual's behaviors. The values are subjective and internal whereas the principles are objective and external.

On a long term the values can change if the individual makes new acquisitions of knowledge and attitudes which he associates with positive or negative experiences in the relations he has been involved in. In spite of their fluctuation, inclinations and emotions have a major role in creating a first impression which is the starting point for trust and relations. The model presents interest for the business environments characterized by quick decisions, incertitude and a high level of risk. It has the advantage of sustaining the role of previous experience, the existence of some different personality structures and the disadvantage of over-evaluation of the importance of first impressions.

The same authors developed the model of the continuum of trust by introducing a new premise to the model of experience of trust, respectively the conditioned trust. This premise appears due to the fact that trying to know the system of values of another takes time and supplementary efforts of communication. Taking into consideration the moment t0 of a relation of conditional trust, the parties can evolve towards an unconditional trust or towards giving up the relation. (see picture 4). We may say that the conditional trust is the minimum starting point from where a relation or partnership can be built, even if supervision and control are required at first. The aspect that the model considers to be implicit is the desire of each party to build a relation which corresponds mainly to the authors' vision than to reality. The target of this model is achieving unconditional trust. This is not translated thorough the congruence of values or / and principles but through creating positive affective states of mind of friendship that are sufficient for the observance of the parties' roles and maximum concentration on task. The model catches the evolution in time of relations and together with the model of experience of trust offers a more satisfactory image of the way in which trust appears and develops in relations.

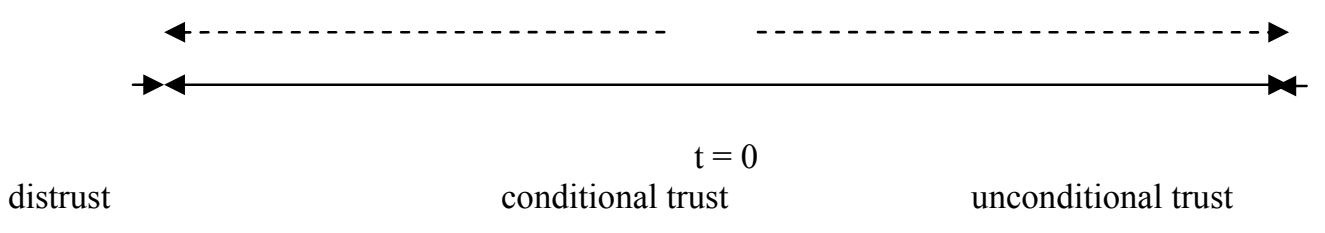

Picture 4. The model of continuum of trust 
Source: Jones, G.R., George, J.M. (1998), The experience and evolution of trust: Implications for cooperation and teamwork, The Academy of Management Review, 23, 3, p. 531-546

The model of equation of trust proposed by Galford and Drappeau (2003) is an equation of instrumental value for the leader of an organization. The model postulates the existence of some dimensions of trust under the conditions when the leader has the necessary abilities to create trust in organizations and these abilities are inter-connected. (see picture 5).

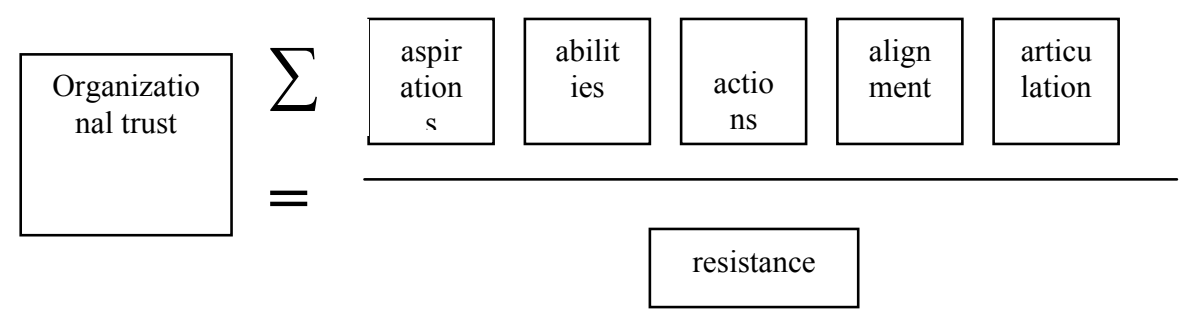

Picture.5. Model of equation of trust

Source: Galford, R., Drappeau, A. (2003), The Trusted Leader: Bringing Out the Best in Your People and Your Company, Simon\&Schuster Adult Publishing Group

The five abilities of a leader should be: aspirations (the leader's ability to identify the peoples' aspirations, aspirations which determine them to work), abilities (ability to aquire the resources that are necessary for the organization and to offer the individuals a vision in perspective), actions (the power not to let the diversions, crises, bankruptcies to appear), alignments (stability, consistency between aspirations and abilities, aspirations and actions, abilities and actions), articulation (preoccupation in maitaining a permanent communication with the colleagues, subordinates, with the entire organization). As a common feature of the concept of resistance there are summerized fear, skepticism, frustration and the views of ,we-and-them' type. Beyond the ideal portrait such a leader should have, the model has the merit of orientation towards ballance as well as the complex, studied correlation of some abilities which require a long process of formation. The general model of trust in organizationsis proposed by Zlate si Avram (2005). (see picture 6).

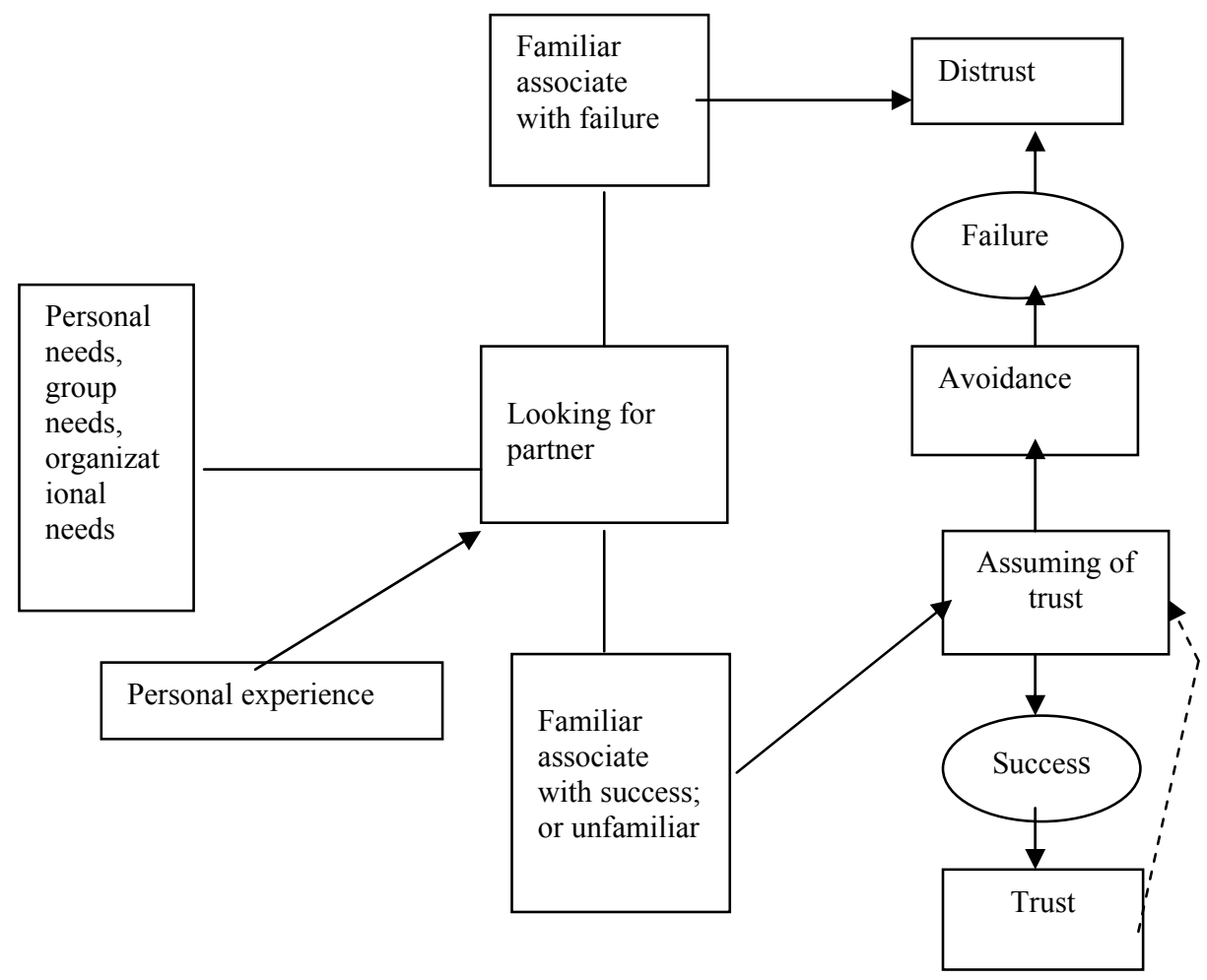




\author{
Picture 6. The general model of trust in organizations \\ Source: Zlate, M., Avram, , E. (2005), The Organizational Trust - some theoretical issues, Journal of \\ Organizational Psychology, vol. V, no. 2-3, p. 11-30
}

Its merit is that of reconsidering the needs of the individual and of correlating them with those of the group and organizations offering a two-exit construct: trust and distrust but without the absence of trust. The subject of this model can take both ways for different types of relations. The key-elements are intentionality justified by the experiences of previos relations and assuming the trust as premise for a possible successful relation. The model of the two Romanian authors starts from the premise that trust is initiated, is assumed and is developed starting from the individual, group and organizational needs in the objective context of work tasks, avoiding to put emphasis on the leader's role and considering that each of the employees has a different set of abilities to relate.

\title{
Organization based on trust
}

The establishing of the organizational climate in the vision of Koys D. and De Cotis T. (1991) can be done by investigating eight dimensions: cohesion, trust, resources, support, acknowledgement, seriousness and innovation. In the organizational context, they defined trust as the perception of freedom of open communication with those from the superior levels of the organization about the delicate and personal problems, considering that it is normal not to break the confidential character of such discussions. The Institute of Personnel and Development (IPD) suggests in the declarationd entitled People Make the Difference (1994) that the edification of trust is the only basis which can lead to an assumed commitment because ,inside too many organizations, the difference between what is said and what is done undetermines the feeling of trust, generates skepticism among employees and shows contradictions in the managerial plan". In 1997 Shaw R. in his work Trust in the balance defines trust as "the conviction that those who we rely on will rise to the level of our expectations”, our expectations being „the extent to which we consider that the person in cause takes responsability in fulfilling our tasks". The organization with a high level of trust was described by Fox A. (1973) in Beyond Contract as that community where employees share certain objectives or values, have all the feeling of some obligations on a long-term towards each other, offer themselves spontaneous support, without calculating in detail how much it costs them or pretending to be returned the favour, communicate sincerely and without restrictions, are ready to put their life into somebody else's hands, give one another the presumption of not being guilty regarding any doubt it might occur regarding the good will and personal motivation. An ideal situation, theoretical and normative, may appear. Reality proves us that trust is in most cases a presumtion of the one who has it. It depends largely on the its possessor ability to manage it efficiently and adequately and even more when we consider trust an instrument of organizational politics. We should not overlook the cultural horizon (space and time) where we talk about trust. Sako M. (1994) in The informational requirement of trust in supplier relations: evidence from Japan, the U.K. and U.S.A., admits that trust has the quality of a "cultural norm which can be but rarely created deliberately" because any technique of inducing trust undermines the foundation of this feeling like a recipe with specific ingredients recognizible only by those educated to perceive them. Trust is a result of a judicious management. (Thompson M. 1998). Starting from the premise that it exists, management has the responsability to develop it by personal example and by a permanent preoccupation to know and anticipate the employees' expectations. Managers would not know how to manage a resource they do not know and could not multiply a capital that is valuable but volatile. More explicitly, trust lies in the employees' availability to involve consequently in the activity of the organization, activity which managers know and evaluate, developing permanently the quality of relations inside the 
organizations they lead. Anticipating a new, more institutionalized dimension of trust in the rythm of changes at the end of the XXth century, Herriott (1998) gives it the role of mediating the relations and support among employees and employers and less the role of an instrument of managing the personnel or the processes. He admits that trust can be lost but, becoming an assumed component of the values of the organization, he develops a four-step program to regain it, addressed mainly to management but implemented on the organization. The consacration of trust has as binder „knowledge”, which is an acknowledgement and acceptance from both parties of the needs and interests of the other one by creating a percetion of seriousness.

\section{Trust and its place among the organization values}

No job description requires us to protect the values of the organization. Though, they are our anchors from the first up to the last working hour. This means that we have the responsability to put all those values in all our decisions and all the actions we take. We will frequently observe the importance of integrity, honesty, consistency and loyalty. The way in which we behave expreses the values we believe in. If there are differences between the personal values and those of the organization, a compromise should be made. The problem becomes „how much moral and emotional dissonance can we take?". On the contrary, when the individual values and those of the organization tend to congruence, performances will soon appear. The term of value correlates the organizational behavior to the personal one. It refers to what people feel that is correct, good, moral, personal and important. Anita Roddick, the founder of Body Shop (1991) underlined the importance of incorporating the values in the daily operationalization of business. Conceptually known as „values-led leadership”, it is based on the idea that organizations must take responsability for their employees and for the community/society that makes their existence possible. Another concept, derived but inspired by values is that of „values-led management”. It refers to the loyalty that the management inspires to its employees and clients. It is not by chance that Fukuyama (1995) prefers to turn his analyses towards the visible, behavioral aspect of trust. Thus, the shared values and norms can be: integrity, the quality of being worthy of respect/pride, compasion and understanding, promptness in action, agreement/consent and procedural justice. Other psycho-organizational variables which contribute to the foundation of trust are: competence, vision, justice/rightousness, safety, security and stability at the workplace, socialization, learning, support and respect. The research on trust and its effects in the organozational environments has an acute practical and applicational character starting from the elements of each organization, tending to combine the newest theoretical approaches with the most efficient models. Surely, as long as trust can bring benefits to the organization, it will be integrated in its indexes of performance.

\section{Bibliography}

1. Armstrong, M.(2003) Management of Human Resources, Codecs Publications, Bucharest

2. Avram, E., Cooper, C.L. (2008) Organizational-managerial Pshychology. Present tendencies. Polirom Publishing, Iaşi

3. Douglas, W., Creed, E., Miles, R.E. (1996) "Trust in organizations - a conceptual framework linking organizational forms, managerial philosophies and the opportunity cost of control" in Kramer, R.M.,Tyler, T. (ed.) Trust in Organizations, Frontiers of Theory and Research, Sage Publications, London

4. Fukuyama, F (1995), Trust: The Social Virtues and the Creation of Prosperity, The Free Press, New York.

5. Galford, R., Drappeau, A.(2003), The Trusted Leader: Bringing Out the Best in Your People and Your Company, Simon\&Schuster Adult Publishing Group. 


\section{Studies and Scientific Researches - Economic Edition, no. 15, 2010}

6. Herriot, P., Hirsh, W. and Riley, P. (1998) Trust and Transition: Managing the employment relationship, Wiley, Chichester

7. Jones, G.R., George, J.M. (1998), “ The experience and evolution of trust: Implications for cooperation and teamwork", The academy of Management review

8. Koys, D., De Cotis, T. (1991) Inductive measures of organizational climate, Human Relations

9. Mayer, R.C., Davis, J.H., Scoorman, F.D.(1995), "An interrogation mode of organizational trust", The Academy of Management Review Briarcliff manor, iulie, vol. 20

10. McGregor, D. (1960) The Human Side of Enterprise, McGraw-Hill, New York

11. Misztal, B.A.(1996) Trust in modern Societies, Polity Press, Cambridge

12. Thompson, M. (1998) Trust and reward, in Trust, Motivation and Commitment: A reader, Ed. S.

Perkis and St.J.Sandrigham, Strategic Remuneration Research Centre, Farringdom, London 